\title{
Effects of Deformation Texture and Twins on the Corrosion Resistance of Rolled AZ31 Mg Alloy Under 5\% Uniaxial Compression
}

\author{
Chen Wang ${ }^{1} \cdot$ Hao Ding ${ }^{1} \cdot$ Bing-Shu Wang ${ }^{1} \cdot$ Kui Wang $^{1} \cdot$ Jing-Jing Shi $^{1} \cdot$ Jun-Feng Chen $^{1}$
}

Received: 4 May 2017/Revised: 4 July 2017/Published online: 29 August 2017

(C) The Chinese Society for Metals and Springer-Verlag GmbH Germany 2017

\begin{abstract}
The deformation texture and twin effect of rolled AZ31 Mg alloy on the corrosion resistance in simulated body fluid (SBF) at room temperature were examined by potentiodynamic polarization and electrochemical impedance spectra. The corrosion morphology evolution after being immersed in SBF for $24 \mathrm{~h}$ has been analyzed by scanning electron microscope. The results show that the inhomogeneous deformation leaded to the obvious differences in the microstructure. The corrosion rate of rolled AZ31 Mg alloy decreased dramatically in the transverse direction (TD) plane, which mainly consisted of $\{0001\}$ deformation texture, making TD plane be a lower surface energy, and thus a higher corrosion resistance, while the corrosion resistance of the plane with $45^{\circ}$ to TD direction (45TD plane) containing enormous $\{10-12\}$ tension twins decreased after 5\% uniaxial compression. The $\{10-12\}$ tension twins accelerate the rate of corrosion procedure and pitting corrosion. Moreover, it is suggested that the deformation texture affects the corrosion behavior more than the twins do. This study indicates that the corrosion rate of AZ31 Mg alloy in SBF can be modified by the small uniaxial compression.
\end{abstract}

KEY WORDS: AZ31 Mg alloy; Twins; Texture; Corrosion resistance

\section{Introduction}

Due to the exceptional lightweight and the high specific strength and stiffness, magnesium $(\mathrm{Mg})$ alloy can be used in a wide range of applications, such as aerospace field and automotive industry. Additionally, with the similar properties to natural bone, and the degradability in vivo through corrosion in the body's electrolyte, $\mathrm{Mg}$ alloys are possible candidates for bone implants, particularly for load-bearing implants $[1,2]$. However, the main reason for the limited applications lies in the bad corrosion resistance in

Available online at http://link.springer.com/journal/40195

Bing-Shu Wang

bswang@fzu.edu.cn

1 College of Materials Science and Engineering, Fuzhou University, Fuzhou 350108, China physiological environment. Hence, for the better usage in this special environment, one of the bright prospects of $\mathrm{Mg}$ and its alloys is to control the rate of corrosion in body environment [3].

The research on wrought magnesium materials mainly pays attention to AZ31 for its significant possibility in commercial practice [4]. Recently, many reported papers focused on both the corrosion properties and the deformation mechanisms of AZ31 Mg alloy. Song et al. [5] focused on the effect of texture on the corrosion resistance of AZ31 Mg alloy and found that the rolling surface was more corrosion resistant than a cross-sectional surface in $\mathrm{NaCl}$ solution. Xin et al. [2, 6] also made a detailed research on the texture influence of AZ31 Mg alloy in $3.5 \% \mathrm{NaCl}$ solution and simulated physiological environment, separately. Aung and Zhou [7] experimentally studied the effect of grain size and twins on the corrosion behavior of AZ31 Mg alloy. Moreover, Ascencio et al. $[8,9]$ investigated the influence of electrolyte renewal and 
immersion time on the corrosion of $\mathrm{Mg}$ alloy in simulated body fluid (SBF). On the other hand, the microstructure and texture evolution of AZ31 during uniaxial loading along different directions have been investigated in early studies [10-17]. Choi et al. [10] studied the orientation of grains and twin bands in the AZ31 Mg alloy under uniaxial compression, during which twins occurred by grains rotation and led to various deformation textures. Wang et al. $[11,12]$ investigated the microstructure, textures and mechanical properties of three different initial texture plates under uniaxial tension and compression, and a strong dependence of the deformation mode (in terms of slip/ twinning activity) on the sample orientation was observed, especially for the $\{10-12\}$ tension twinning. All these studies aim at the texture and twin mechanisms of $\mathrm{AZ} 31 \mathrm{Mg}$ alloy during deformation; however, there is limited work with systematic investigation focusing on the effect of the small uniaxial compression with the corresponding variations in deformation textures and twins on $\mathrm{Mg}$ alloy corrosion behavior.

Therefore, the goal of this research is to investigate both the deformation texture and the twin effects on the corrosion resistance of commercial availability AZ31 Mg alloy after small uniaxial compression in simulated physiological environment. By observation from different surfaces $\left(0^{\circ}\right.$, $45^{\circ}$ and $90^{\circ}$ ) with different levels of deformation textures and twins, it is of more intuitive comparison on the corrosion behavior of AZ31 Mg alloy after uniaxial compression, and this helps us to get a better understanding of the corrosion behavior, deformation mechanism and their relationship.

\section{Experiments and Methods}

\subsection{Sample Preparation and Characterization}

The material used in this study was the rolled AZ31 Mg alloy. The as-received $\mathrm{Mg}$ plate was first given a homogenization annealing at $400{ }^{\circ} \mathrm{C}$ for $10 \mathrm{~h}$. The plate was then hot rolled from 161 to $70 \mathrm{~mm}$, followed by a further annealing at $400{ }^{\circ} \mathrm{C}$ for $1 \mathrm{~h}$. Eight test specimens in a prism shape with a dimension of $10 \mathrm{~mm} \times 5 \mathrm{~mm}$ (side length $\times$ thickness) were cut from a large homogenized plate.

The initial texture of the sample was measured by electron backscatter diffraction (EBSD), and the sample exhibits an intense (0001) basal texture (Fig. 1b). Moreover, the initial structure reveals equiaxed grain morphology with an average grain size of $38.4 \mu \mathrm{m}$, as shown in Fig. 1a. The length, width and thickness directions of the samples are defined as the transverse direction (TD), rolling direction (RD) and normal direction (ND), respectively. The specimens were uniaxial compressed along the TD to a strain of $5 \%$ at a loading rate of $1 \mathrm{~mm} /$ min at room temperature. The observation was carried out on three different surfaces with angles of $90^{\circ}$ (TD plane), $45^{\circ}$ (45TD plane) and $0^{\circ}$ (RD plane) to TD direction, respectively, as shown in Fig. 1c.

\subsection{Experimental Processing}

The textures and orientation maps were collected on the polished surfaces by a Supra 55 scanning electron microscope equipped with HKL Channel 5 automated EBSD analysis system. After deformation, the samples were mechanically ground by $\mathrm{SiC}$ sandpapers followed by electro-polishing in an AC-2 solution. The electro-polishing was carried out at $0{ }^{\circ} \mathrm{C}$ with a voltage of $20 \mathrm{~V}$ and a current of $0.5 \mathrm{~A}$ for $40-50 \mathrm{~s}$.

Electrochemical impedance spectra (EIS) measurements were performed in simulated body fluid (SBF) $(\mathrm{NaCl}$ $8.035 \mathrm{~g} / \mathrm{L}, \mathrm{NaHCO}_{3} 0.355 \mathrm{~g} / \mathrm{L}, \mathrm{KCl} 0.225 \mathrm{~g} / \mathrm{L}, \mathrm{K}_{2} \mathrm{HPO}_{4}$ $3 \mathrm{H}_{2} \mathrm{O} 0.231 \mathrm{~g} / \mathrm{L}, \mathrm{MgCl}_{2} \cdot 6 \mathrm{H}_{2} \mathrm{O} 0.311 \mathrm{~g} / \mathrm{L}, \mathrm{CaCl}_{2} 0.292 \mathrm{~g} /$ $\mathrm{L}, \mathrm{Na}_{2} \mathrm{SO}_{4} 0.072 \mathrm{~g} / \mathrm{L}$ ) buffered at $\mathrm{PH}$ values of 7.2-7.4 using tris-hydroxymethyl aminomethane $\left(\left(\mathrm{HOCH}_{2}\right)_{3-}\right.$ $\left.\mathrm{CNH}_{2}\right)$ and hydrochloric acid $(\mathrm{HCl})$ at $37^{\circ} \mathrm{C}$ [18-20]. Potentiodynamic polarization and EIS were tested by using a 660D electrochemical analyzer workstation. A standard three-electrode cell was used, which consisted of a magnesium sample as a working electrode, a platinum sheet $(20 \mathrm{~mm} \times 20 \mathrm{~mm})$ counter electrode and a saturated calomel reference electrode. The exposed area of the working electrode in SBF was $0.5 \mathrm{~cm}^{2}$. The value of the current density for the potentiodynamic polarization curve was calculated as the value of current divided by the exposed area. The potentiodynamic scanning was performed at a rate of $0.01 \mathrm{~V} / \mathrm{s}$ after the cell was held at the open-circuit potential (OCP) for $10 \mathrm{~min}$. At the same time, EIS measurements were executed over the frequency ranged from $100 \mathrm{kHz}$ to $10 \mathrm{MHz}$ with $5 \mathrm{mV}$ of amplitude of sinusoidal potential signals with respect to the OCP.

A specimen was immersed in $100 \mathrm{~mL}$ simulated body solution at room temperature according to ASTM-G31-72 [21]. Before the immersion test, each of the measured surfaces which are previously mentioned in Fig. 1c was mechanically polished up to 1400 -grit $\mathrm{SiC}$ papers and then washed with ethanol to obtain clean testing surfaces. The immersion was carried out without vibration or agitation for $24 \mathrm{~h}$. Then, microstructure and morphology of the corroded surfaces were characterized using a Supra 55 scanning electron microscope (SEM) coupled with the energy-dispersive spectroscopy (EDS) system. X-ray diffraction (XRD, Miniflex600) with $\mathrm{Cu} K_{\alpha}$ radiation was used to identify the corrosion product powders which were scraped from each surface. The water contact angle 

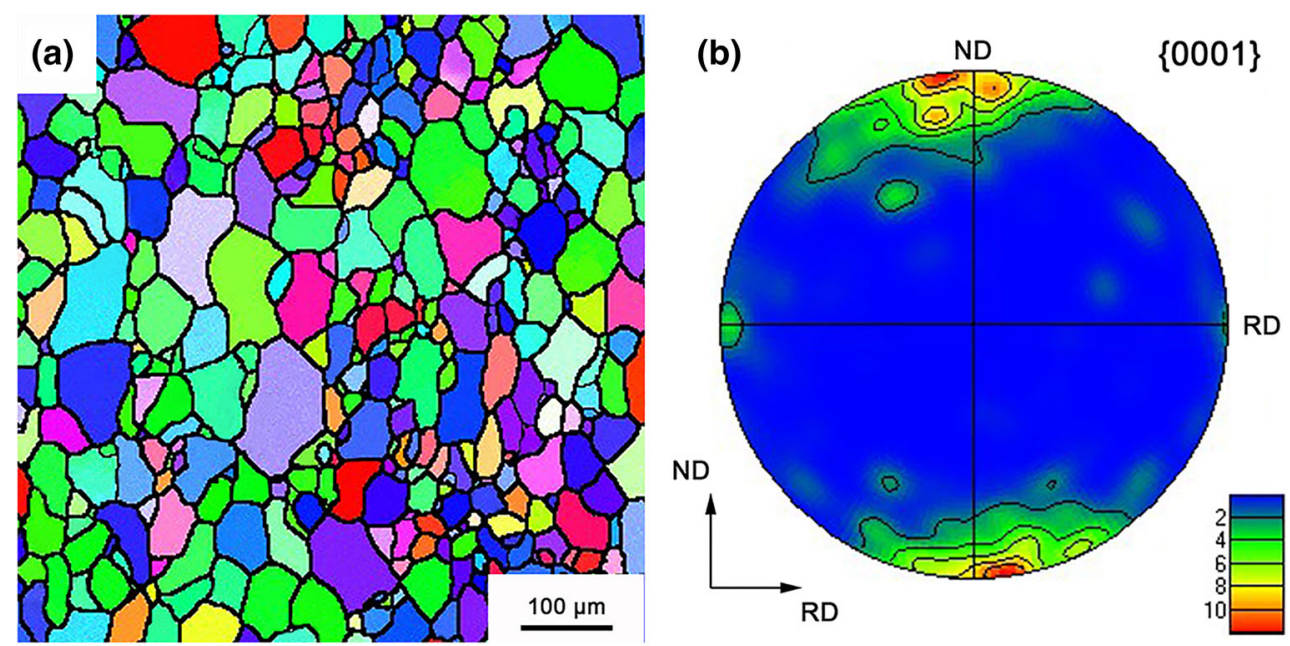

(c)

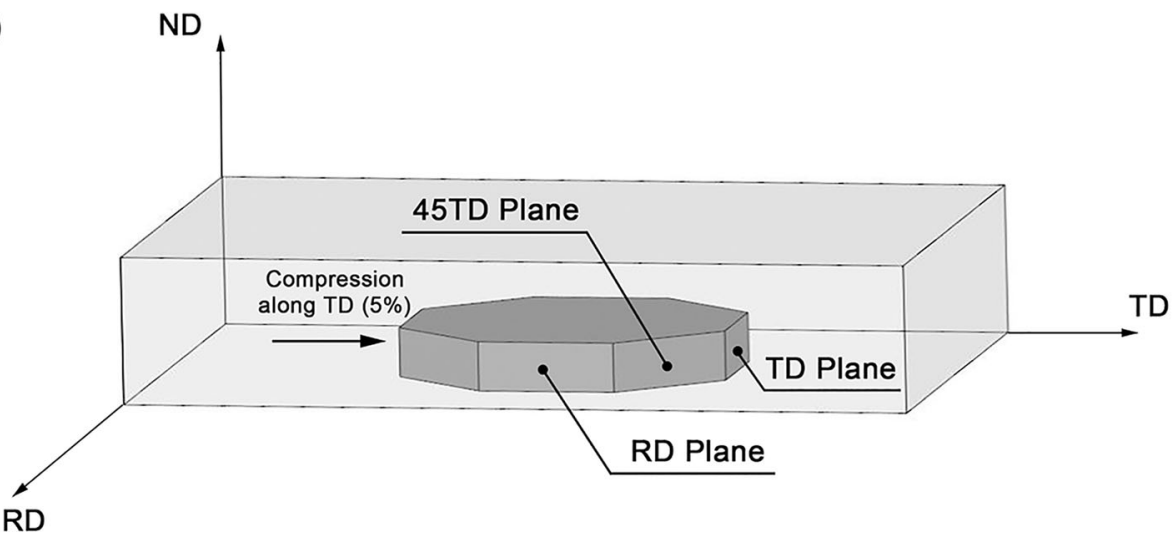

Fig. 1 a Microstructure and texture of the as-received AZ31 Mg sample; b $\{0001\}$ plot figure of as-received AZ31 Mg sample; c schematic illustration of the sample preparation from the large homogenized plate

between the distilled water and the different planes of $\mathrm{Mg}$ sample was measured by SL200B contact angle measurement.

\section{Results and Discussion}

\subsection{Microstructure}

The average grain sizes of AZ31 Mg alloy after compression were measured from the twin boundary maps by a linear intercept method, and they are 37.7, 37.8 and $38.0 \mu \mathrm{m}$ for TD plane, 45TD plane and RD plane (Fig. 2ac), respectively. It is seen that the average grain sizes of the three planes of AZ31 Mg alloy samples are very close at the smaller deformation, which may neutralize the effect of grain size on the corrosion resistance at different surfaces of $\mathrm{Mg}$ alloy as reported in early studies [7]. Meanwhile, many twins can be observed in three planes under $5 \%$ uniaxial compression. Apart from the main $\{10-12\}$ tension twin boundaries, there were many different twin variants inside the same grain: red lines indicate the $\{10-12\}$ twin boundaries, yellow lines indicate the $\{10-12\}-\{01-12\}$ twin variant boundaries, green lines indicate the $\{10-12\}-\{0-112\}$ twin variant boundaries and gray lines indicate the $\{10-12\}-\{-1012\}$ twin variant boundaries. It is shown in Table 1 that the percentage of $\{10-12\}$ twin boundaries in the 45TD plane is about 1.37 times as high as that in the TD plane, and the RD plane presents the least twin boundaries after compression.

Figure 3 illustrates the microstructure and texture in the three kinds of specimens compressed at room temperature and at a strain of $5 \%$. Orientation image maps (OIM) illustrate the angles between $c$-axis of grains and compression direction. It can be observed that the grains are split into small pieces with different sizes by twins, resulting in the amount of twin boundaries in the three planes following 45TD plane $>$ TD plane $>$ RD plane. Figure $3 \mathrm{a}$ indicates that the $\{0001\}$ orientations in most grains of TD plane surface are concentrated to TD direction, showing a strong $\{0001\}$ texture parallel to TD axis. It was determined that the $\{0001\}$ orientation would rotate 

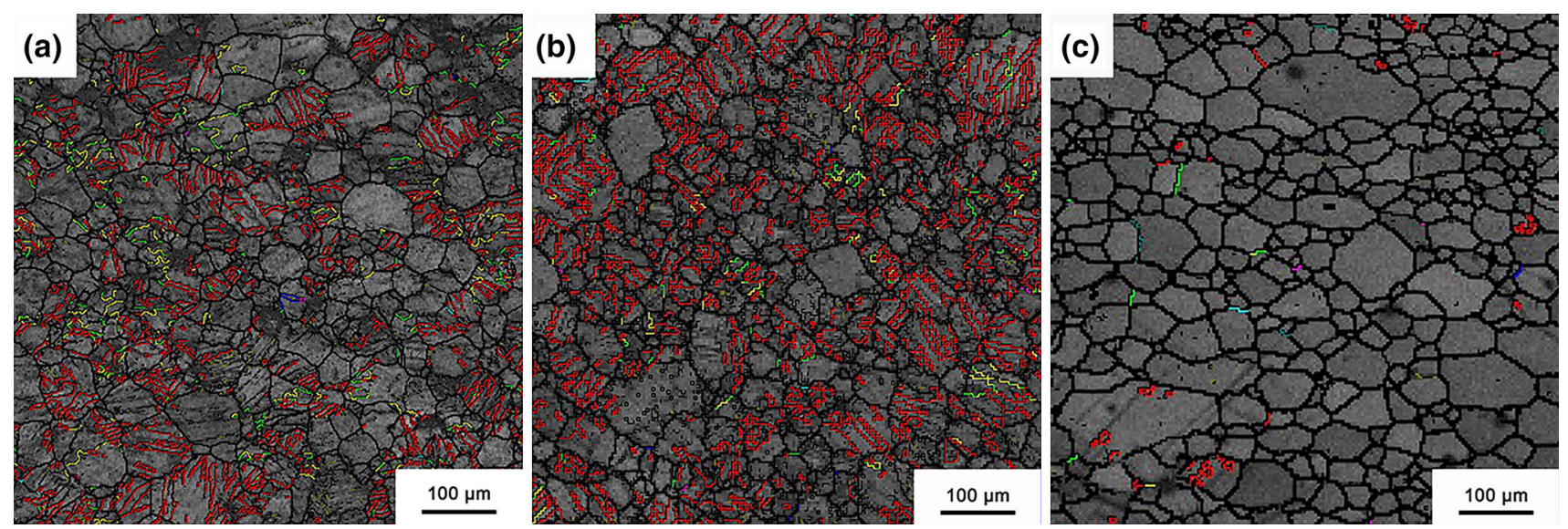

Fig. 2 Twin boundary maps: a TD plane, b 45TD plane, c RD plane of AZ31 Mg sample after 5\% uniaxial compression

Table 1 Percentages of $\{10-12\}$ twin boundaries generated during $5 \%$ uniaxial compression among the total boundaries in different planes

\begin{tabular}{llll}
\hline Type of twins & TD plane & 45TD plane & RD plane \\
\hline$\{10-12\}$ & $16.53 \%$ & $22.58 \%$ & $2.18 \%$ \\
\hline
\end{tabular}

the $c$-axis by $86^{\circ}$ away from the sheet normal to be almost parallel to the compression axis $[22,23]$. The crystallographic orientation of most grains in the 45TD plane, however, is more widely dispersed, as shown in Fig. 3e. This surface is mainly composed of $\{-12-10\}$ and $\{01-10\}$ prism planes, and only a small number of tilt basal textures are exposed in the 45TD plane. Moreover, there is no significant difference in the orientation of the $\mathrm{RD}$ plane after compression deformation compared with that in the as-received AZ31 Mg alloy plate (Fig. 3f).

The misorientation angle distribution (MAD) in Fig. 4a, $\mathrm{b}$ indicates that there are two peaks at angle ranges of $55^{\circ}$ $60^{\circ}$ and $85^{\circ}-90^{\circ}$ in both the TD plane and the 45TD plane surfaces. The range of the boundary misorientation existed at $54^{\circ}-58^{\circ}$ along the $\{01-10\}$ axis and at $84^{\circ}-88^{\circ}$ about the $\{-12-10\}$. Apart from these two peaks, the MAD pillars of the two planes are basically the same. Compared with the TD plane, the peaks of 45TD plane are much stronger at $85^{\circ}-90^{\circ}$, while lower at $55^{\circ}-60^{\circ}$, and the rotational axis of the $\{10-12\}$ tension twins is $\{-12-10\}$ $86^{\circ}$ [10]. Besides, $\{01-10\}$ represents the rotational axis of $\{10-12\}-\{0-112\}$ and $\{10-12\}-\{01-12\}$ twin variants. This further confirms that the density of $\{10-12\}$ tension twins is much higher in the 45TD plane surface and the TD plane surface contains more twin variants. The misorientation angle distribution in Fig. $4 \mathrm{c}$ indicates that the RD plane exhibits a random distribution of grain boundaries with no dominant misorientation axis. Table 2 shows that the TD plane mainly consists of $\{0001\}$ deformation texture with $72 \%$ volume faction of twins. However, no obvious compressive double twin boundaries can be found in this study.

\subsection{Potentiodynamic Polarization}

In order to evaluate the corrosion resistance of three different planes, potentiodynamic polarization tests were performed and provided a view of pitting corrosion when the AZ31 Mg alloy is placed in SBF, as shown in Fig. 5, and the growth rate of electric current densities becomes higher when the scanning potential reaches the turning points, as the arrows show in Fig. 5. Compared with the TD and RD planes, the pitting potential value of the 45TD becomes the most negative. And the pitting potential of RD plane is a little lower than that of the TD plane. The corrosion current density $\left(I_{\text {corr }}\right)$ is determined from the intersection of extrapolated cathodic and anodic Tafel lines at the corrosion potential $\left(E_{\text {corr }}\right)$ [24]. The polarization resistance $\left(R_{\mathrm{P}}\right)$, which is directly proportional to the corrosion resistance, can be obtained by the simplified Stern-Geary relationship $[25,26]$ using the anodic/cathodic Tafel slopes $\left(b_{\mathrm{a}}\right.$ and $\left.b_{\mathrm{c}}\right)$ :

$R_{\mathrm{P}}=\frac{b_{\mathrm{a}} b_{\mathrm{c}}}{2.303 I_{\text {corr }}\left(b_{\mathrm{a}}+b_{\mathrm{c}}\right)}$.

Table 3 summarizes all the corrosion parameters obtained from the potentiodynamic polarization curves. The lowest corrosion potentials and the highest corrosion current densities of the 45TD plane imply that the faster the corrosion rate, the more negative corrosion resistance it will be. The TD plane, however, exhibits the most positive $E_{\text {corr }}$ of $-1.496 \mathrm{~V}$ and the lowest $I_{\text {corr }}$ of $3.086 \times 10^{-6} \mathrm{~A} /$ $\mathrm{cm}^{2}$. Compared with the 45TD plane, the corrosion potential of the TD plane shifted above $27 \mathrm{mV}$, and the corrosion current density is decreased to its half. The value 

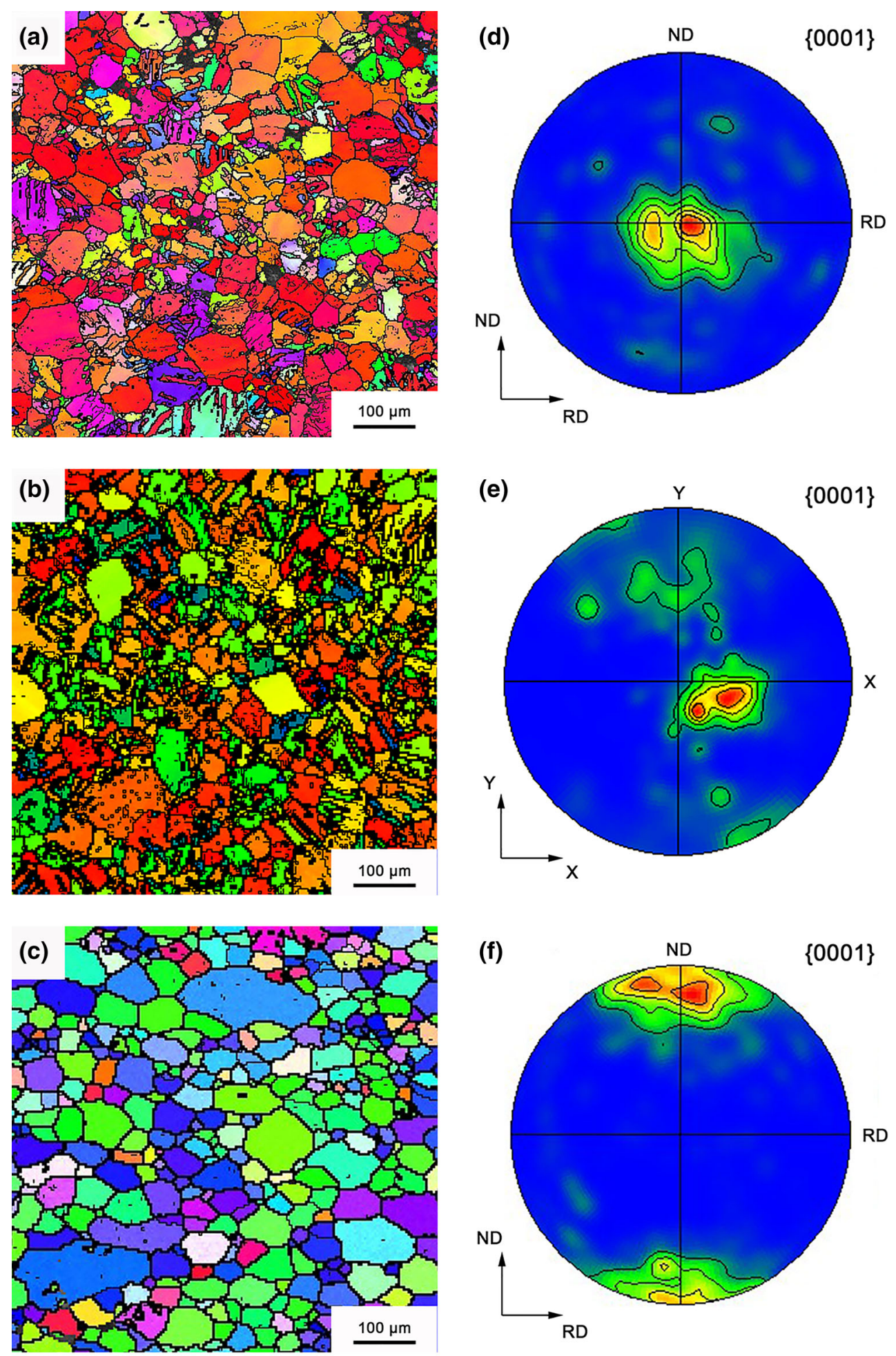

(g)

c// CD

Fig. 3 Orientation image maps: a TD plane, b 45TD plane, $\mathbf{c}$ RD plane; $\{0001\}$ and $\{11-20\}$ plot figures: d TD plane, e $45 T D$ plane, f RD plane of AZ31 Mg sample after 5\% uniaxial compression; the colors of the grains in the maps a-c correspond to the crystallographic axes of the grains 

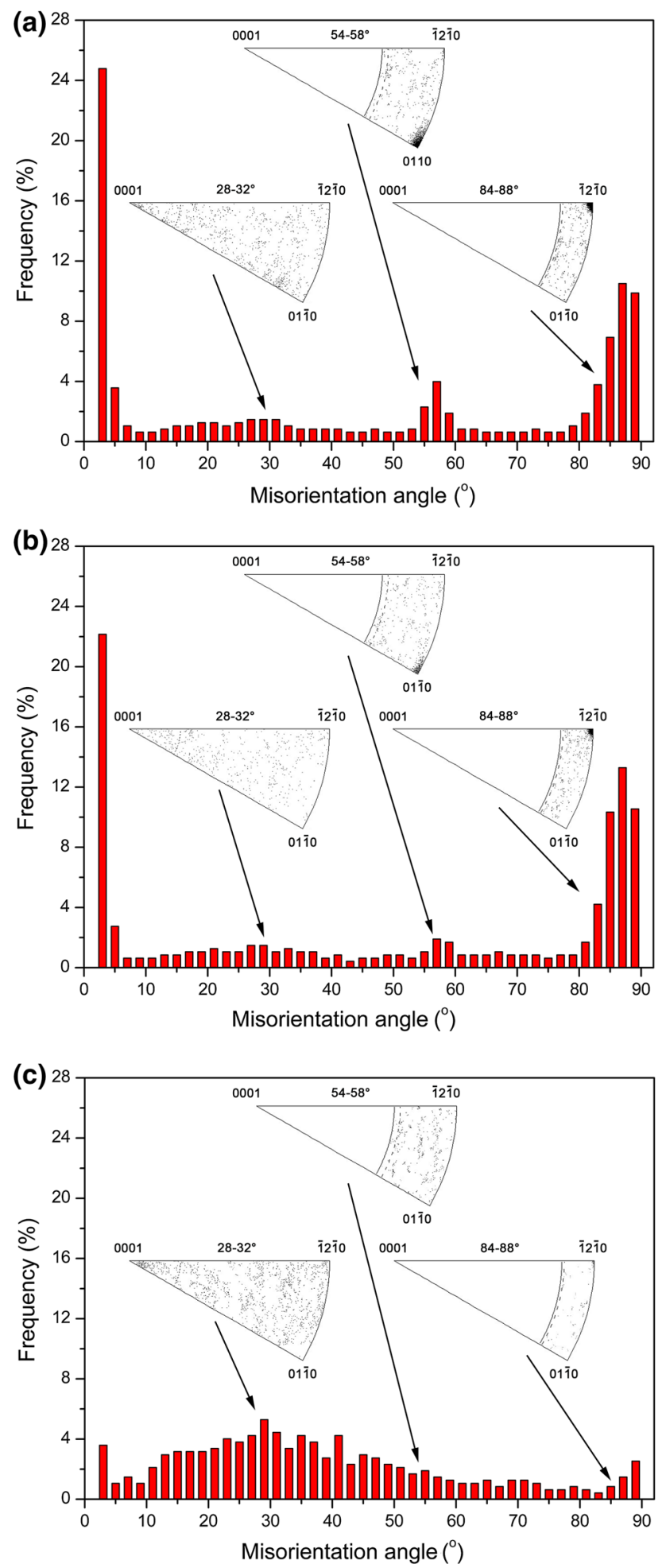

Fig. 4 Distribution of misorientation angle between grain boundaries: a TD plane, b 45TD plane, c RD plane of AZ31 Mg sample after $5 \%$ uniaxial compression

of $R_{\mathrm{P}}$ of RD plane is found between those of TD and 45TD planes. Therefore, it is the fact that the TD plane has a higher corrosion resistance than other two planes.
Table 2 Volume fractions of twins in different planes for the sample after $5 \%$ uniaxial compression

\begin{tabular}{lll}
\hline TD plane & 45TD plane & RD plane \\
\hline $72 \%$ & $59 \%$ & $2 \%$ \\
\hline
\end{tabular}

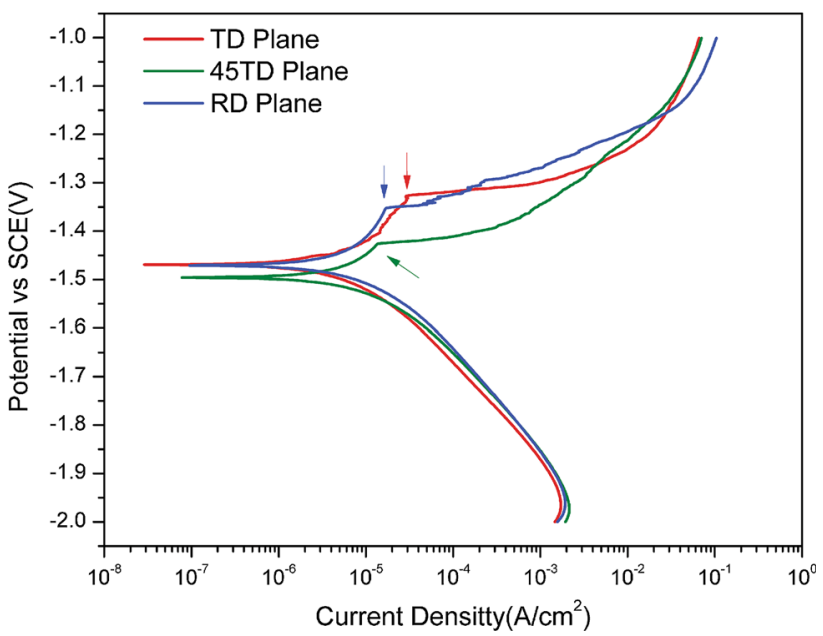

Fig. 5 Potentiodynamic polarization curves of different planes of AZ31 Mg sample (after 5\% uniaxial compression) in SBF solution

\subsection{Electrochemical Impedance Spectra}

To confirm the results above, EIS was carried out to evaluate the corrosion performance of the TD, 45TD and RD planes in the SBF. Figure 6 shows the Nyquist plot (a), the Bode plots $(b, c)$ and the simulated equivalent circuit (d) of the TD, 45TD and RD planes. All of the EIS curves consist of a low-frequency capacitive section, which can be attributed to the well-known negative difference effect (NDE) and relaxation of adsorbed $\mathrm{Mg}^{2+}$ ions [27]. Ascencio et al. [9] and Shi et al. [20] reported the similar Nyquist and Bode diagrams for the WE43 Mg alloy and the AZ31 Mg alloy with Ca-P sol-gel coating. So, the same fitting equivalent electrical circuit was adopted in this study, as shown in Fig. 6d. In order to better fit the experimental data, a constant phase element (CPE) was used to model the electrode capacitive behavior. CPE is often used to describe a non-ideal capacitive behavior due to different factors such as surface roughness and heterogeneities, electrode porosity, variation of coating composition, slow adsorption reactions or a non-uniform potential and current distribution [8,28-31]. The impedance of a CPE was used to replace the capacitance for remitting the "scatter effect" of electrode/electrolyte interface. The formula of CPE impedance can be expressed as following $[8,32]$ :

$Z_{\mathrm{CPE}}=Q^{-1}(j w)^{-n} \quad$ with $\quad-1 \leq n \leq 1$, 
Table 3 Results obtained from potentiodynamic polarization curves of different planes of AZ31 Mg sample (after 5\% uniaxial compression) in SBF solution

\begin{tabular}{|c|c|c|c|c|c|}
\hline Planes & $b_{\mathrm{a}}(\mathrm{mV})$ & $b_{\mathrm{c}}(\mathrm{mV})$ & $E_{\text {corr }}(\mathrm{V}$ vs SCE $)$ & $I_{\text {corr }}\left(\mathrm{A} / \mathrm{cm}^{2}\right)$ & $\overline{R_{\mathrm{P}}\left(\Omega \mathrm{cm}^{2}\right)}$ \\
\hline TD plane & 0.3560 & 0.4076 & -1.469 & $3.086 \times 10^{-6}$ & $2.674 \times 10^{4}$ \\
\hline 45TD plane & 0.3939 & 0.5478 & -1.496 & $6.500 \times 10^{-6}$ & $1.531 \times 10^{4}$ \\
\hline RD plane & 0.5890 & 0.5391 & -1.471 & $5.662 \times 10^{-6}$ & $2.159 \times 10^{4}$ \\
\hline
\end{tabular}
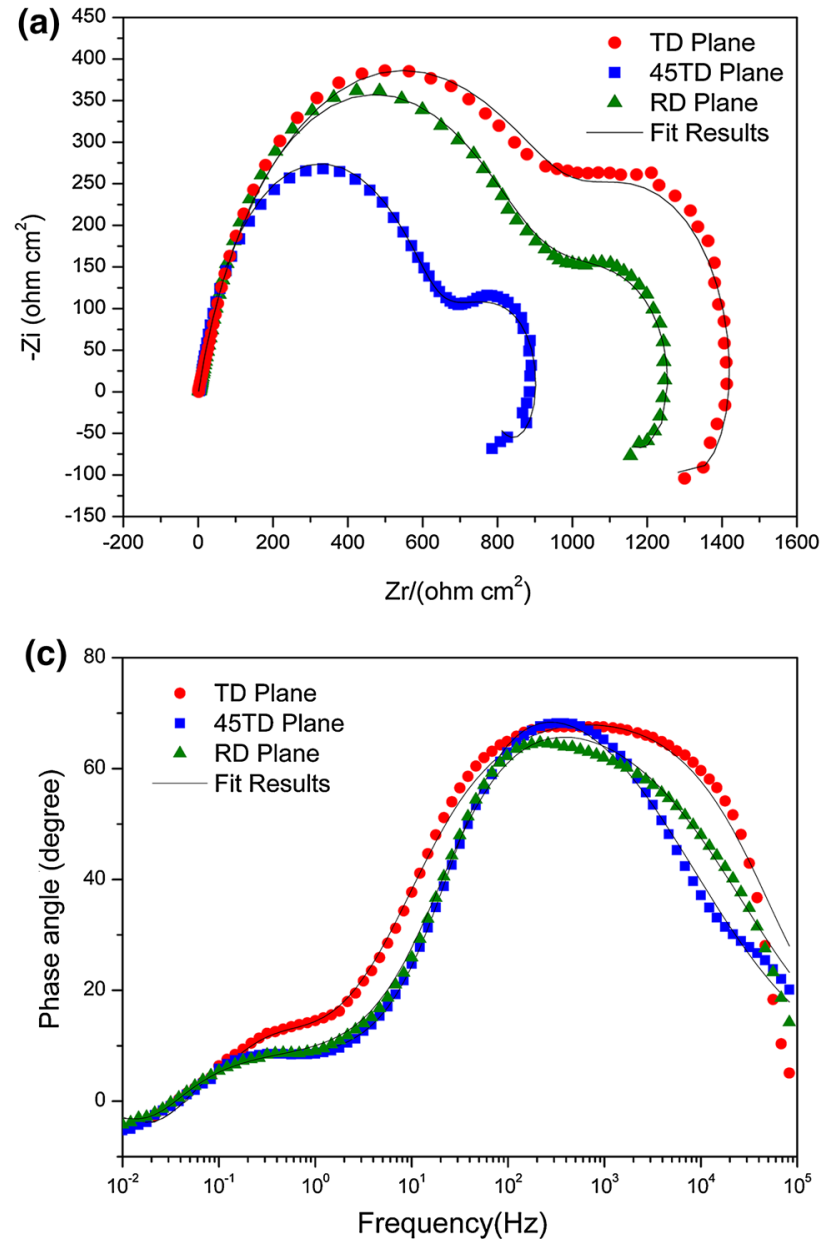

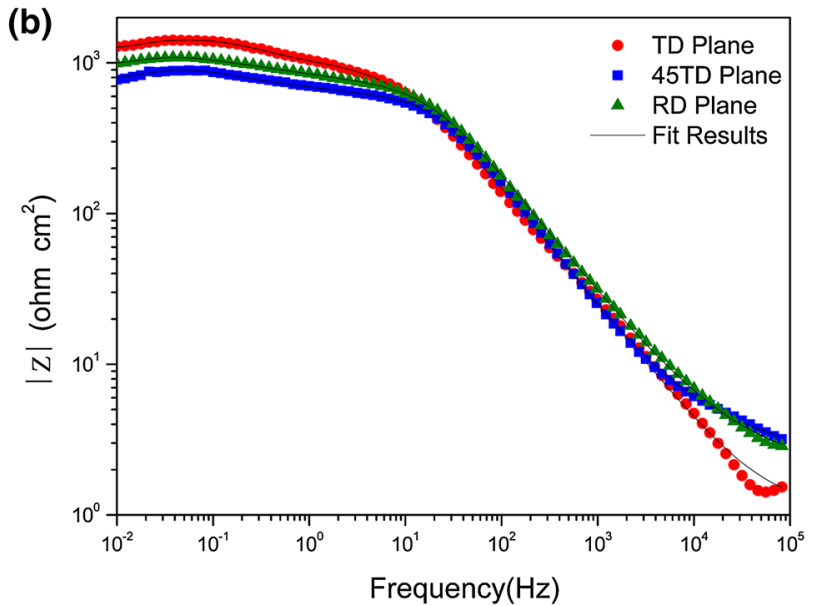

(d)

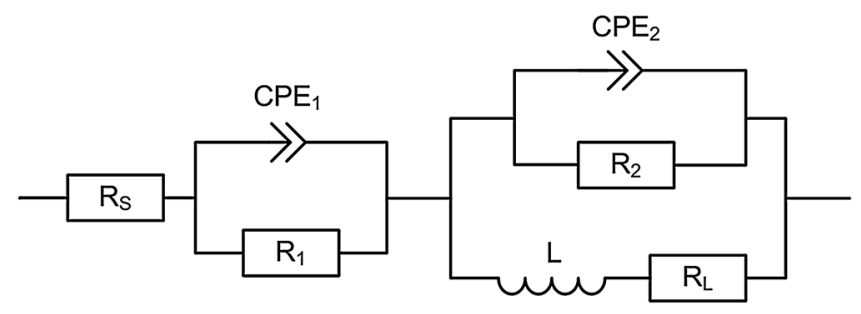

Fig. 6 EIS diagrams for the TD, 45TD and RD planes of AZ31 Mg sample (after 5\% uniaxial compression) in SBF solution: a Nyquist plot, b Bode plot of $|Z|$ versus frequency, c Bode plot of phase angle versus frequency, $\mathbf{d}$ simulated equivalent circuit

where $Z$ is the $\mathrm{CPE}$ impedance, $Q$ is the $\mathrm{CPE}$ constant, $j$ is the imaginary number, $\omega$ is the angular frequency $(\omega=2 \pi f)$ and $n$ takes a value between 0 and 1. An ideal capacitor behavior yields $n=1$, a resistor yields $n=0$ and an inductor yields $n=-1$.

In the equivalent circuit, $R_{\mathrm{s}}$ is the electrolyte solution resistance between the working and reference electrodes. The $R_{1}$ and the constant phase elements $\mathrm{CPE}_{1}$ describe the diffusion of $\mathrm{Mg}^{2+}$ species through the corrosion layer. The $R_{2}$ and $\mathrm{CPE}_{2}$ describe the charge transfer process at the substrate/electrolyte interface [33]. The $L$ and $R_{\mathrm{L}}$ demonstrate the induction and induction resistance in the system, respectively. The equivalent electrical circuits suggested in this work have a good correlation with results obtained by various scientific groups dealing with fitting of impedance spectra [30-33]. The values of the equivalent circuit elements are summarized in Table 4. In order to ensure the goodness of fitness for each sample, the Chisquare values were calculated which were in the order of $10^{-4}$. The $R_{1}$ and $R_{2}$ correspond to the corrosion resistance properties of the planes. It can be seen that the TD plane has higher $R_{2}$ and $R_{1}$ values than other planes, and the 
Table 4 Fitting parameters of different planes of AZ31 Mg sample (after 5\% uniaxial compression) in SBF solution

\begin{tabular}{|c|c|c|c|c|c|c|c|c|c|c|}
\hline Planes & $\begin{array}{l}R_{\mathrm{e}} \\
\left(\Omega / \mathrm{cm}^{2}\right)\end{array}$ & $\begin{array}{l}Q_{1} \\
\left(\Omega^{-1} / \mathrm{cm}^{2} \mathrm{~s}^{\mathrm{n}}\right)\end{array}$ & $n_{1}$ & $\begin{array}{l}R_{1} \\
\left(\Omega \mathrm{cm}^{2}\right)\end{array}$ & $\begin{array}{l}Q_{2} \\
\left(\Omega^{-1} / \mathrm{cm}^{2} \mathrm{~s}^{\mathrm{n}}\right)\end{array}$ & $n_{2}$ & $\begin{array}{l}R_{2} \\
\left(\Omega \mathrm{cm}^{2}\right)\end{array}$ & $\begin{array}{l}R_{\mathrm{L}} \\
\left(\Omega \mathrm{cm}^{2}\right)\end{array}$ & $\begin{array}{l}L \\
\left(\mathrm{H} / \mathrm{cm}^{2}\right)\end{array}$ & $\chi^{2}$ \\
\hline TD plane & 2.08 & $3.969 \times 10^{-5}$ & 0.89 & 728.3 & $4.416 \times 10^{-5}$ & 0.79 & 920.8 & 450.2 & 42.6 & $6.0 \times 10^{-4}$ \\
\hline 45TD plane & 2.28 & $1.727 \times 10^{-5}$ & 0.93 & 554.6 & $2.253 \times 10^{-5}$ & 0.92 & 616.7 & 903.5 & 112.3 & $2.1 \times 10^{-4}$ \\
\hline RD plane & 2.19 & $2.357 \times 10^{-5}$ & 0.86 & 644.8 & $2.375 \times 10^{-5}$ & 0.85 & 800.2 & 835.4 & 102.5 & $3.8 \times 10^{-4}$ \\
\hline
\end{tabular}

value of $R_{2}$ of TD plane is 1.8 times as high as that of 45TD plane, indicating the improvement in corrosion resistance to protect the $\mathrm{Mg}$ alloy substrate against corrosion.

\subsection{Corrosion Products Characterization}

The morphologies of the different planes of AZ31 Mg sample immersed in SBF for $24 \mathrm{~h}$ were observed. As shown in Fig. 7, the corrosion production is uniformly distributed on the surface of TD plane, and there are only a few whitish corrosion products sticking to the relatively smooth surface (Fig. 7a). However, the coating of the RD plane is not as smooth as that of TD planes, and the number and size of the whitish spots become more and bigger as shown in Fig. 7b. Moreover, the whitish spots were distributed widely in the RD plane, and these results reveal that the trend to form pitting in the RD plane is stronger than that in the TD plane [9]. Furthermore, the surface of corroded 45TD plane is very rough, as shown in Fig. 7c. And many cracks and whitish spots are observed on the surface, which suggests the occurrence of the serious corrosion. The cracks are formed due to the dehydration of the corrosion layer during the analysis in vacuum [34]. Figure $7 d$ is the local area magnification for an etching pit in Fig. 7c. The etching pit is irregularly rounded with a diameter of about $115 \mu \mathrm{m}$. The formation of etching pits could be due to the peeling-off of corrosion products from the sample surfaces [10]. Red squares in Fig. 7 show the areas where EDS analysis was performed, and the results are shown in Table 5. Compared with spot 1 of the TD plane (Fig. 7a), the presence of $\mathrm{O}$, $\mathrm{Mg}, \mathrm{Al}, \mathrm{P}, \mathrm{Ca}$ and $\mathrm{Na}$ at spot 2 can be seen. However, what different at spot 2 is the presence of $\mathrm{Na}$ and the increase in percentage of $\mathrm{O}, \mathrm{P}$ and $\mathrm{Ca}$. At spot 3 of the RD plane (Fig. 7b), it does not show significant difference to that of spot 2 in Fig. 7a, but it shows higher O, P and $\mathrm{Ca}$ contents, indicating more severe corrosion at spot 3 than that at spot 2. The EDS results of spot 4 of the 45TD plane present the absence of $\mathrm{Al}$ and the existence of $\mathrm{Cl}$, revealing the contribution of chloride ions in the acceleration of the localized corrosion [8, 35]. The finding further confirms the existence of more localized, severe and irregular pitting in the 45TD plane, and thus, the behavior is more negative than other two planes.
The XRD spectra (as shown in Fig. 8) indicate that, for all the three planes, the corrosion products consist of $\mathrm{Mg}(\mathrm{OH})_{2},(\mathrm{Ca}, \mathrm{Mg})_{3}\left(\mathrm{PO}_{4}\right)_{2}$ and $(\mathrm{Ca}, \mathrm{Mg}) \mathrm{CO}_{3}$ phases. The 45TD plane exhibits the strongest peak of $\mathrm{Mg}(\mathrm{OH})_{2}$, and the TD plane exhibits the lowest peak of $\operatorname{Mg}(\mathrm{OH})_{2}$. This result also indicates that the TD plane has the best corrosion resistance than the $45 \mathrm{TD}$ and RD planes.

The results demonstrate that the 45TD plane exhibits a lower corrosion resistance compared with the TD plane which mainly consists of $\{0001\}$ texture after $5 \%$ uniaxial compression, and this can be interpreted by the surface energy. The $(0001)$ plane $\left(1.13 \times 10^{19}\right.$ atoms $\left./ \mathrm{m}^{2}\right)$ possesses the higher atomic density than (11-20) $\left(6.94 \times 10^{18}\right.$ atoms $\left./ \mathrm{m}^{2}\right)$ and (10-10) $\left(5.99 \times 10^{18}\right.$ atoms/ $\mathrm{m}^{2}$ ) planes [24]. But it is known that the surface of higher atomic density has lower surface energy, and according to the model proposed by $\mathrm{Fu}$ et al. [36], the surface energy values of (0001), (10-10) and (11-20) surfaces of $\mathrm{Mg}$ alloys are $1.808,1.868$ and $2.156 \mathrm{eV} / \mathrm{nm}^{2}$, respectively, which can be transformed into $1.54 \times 10^{4}, 3.04 \times 10^{4}$ and $2.99 \times 10^{4} \mathrm{~J} / \mathrm{mol}$, respectively. According to previous literature, a higher energy surface of metal is beneficial to the adsorption of hydrogen ions and thus promoting the hydrogen evolution reaction [5, 37, 38].

The surface energy of metallic material can be evaluated by the water contact angle measurement. A higher contact angle implies a lower surface energy and more hydrophobic nature of sample. The water contact angles of TD, $45 \mathrm{TD}$ and $\mathrm{RD}$ planes are $36.9^{\circ}, 25.8^{\circ}$ and $26.8^{\circ}$, respectively. Thus, the TD plane has the lowest surface energy which is helpful to increase the corrosion resistance.

Based on the results mentioned above, the strong $\{0001\}$ deformation texture in the TD plane with low surface energy is the main reason why the TD plane has high corrosion resistance. On the other hand, there are numerous twin boundaries in the 45TD plane. The twin boundary is a kind of defect which could increase the electrochemical activity of 45TD plane, leading to the decrease in corrosion resistance. The corrosion performance of different planes for AZ31 Mg sample depends on not only the crystallographic orientation but also the twin boundaries. The small uniaxial compression can change the textures and the twins in difference planes, thus changing the corrosion resistance of AZ31 Mg alloy in SBF. 

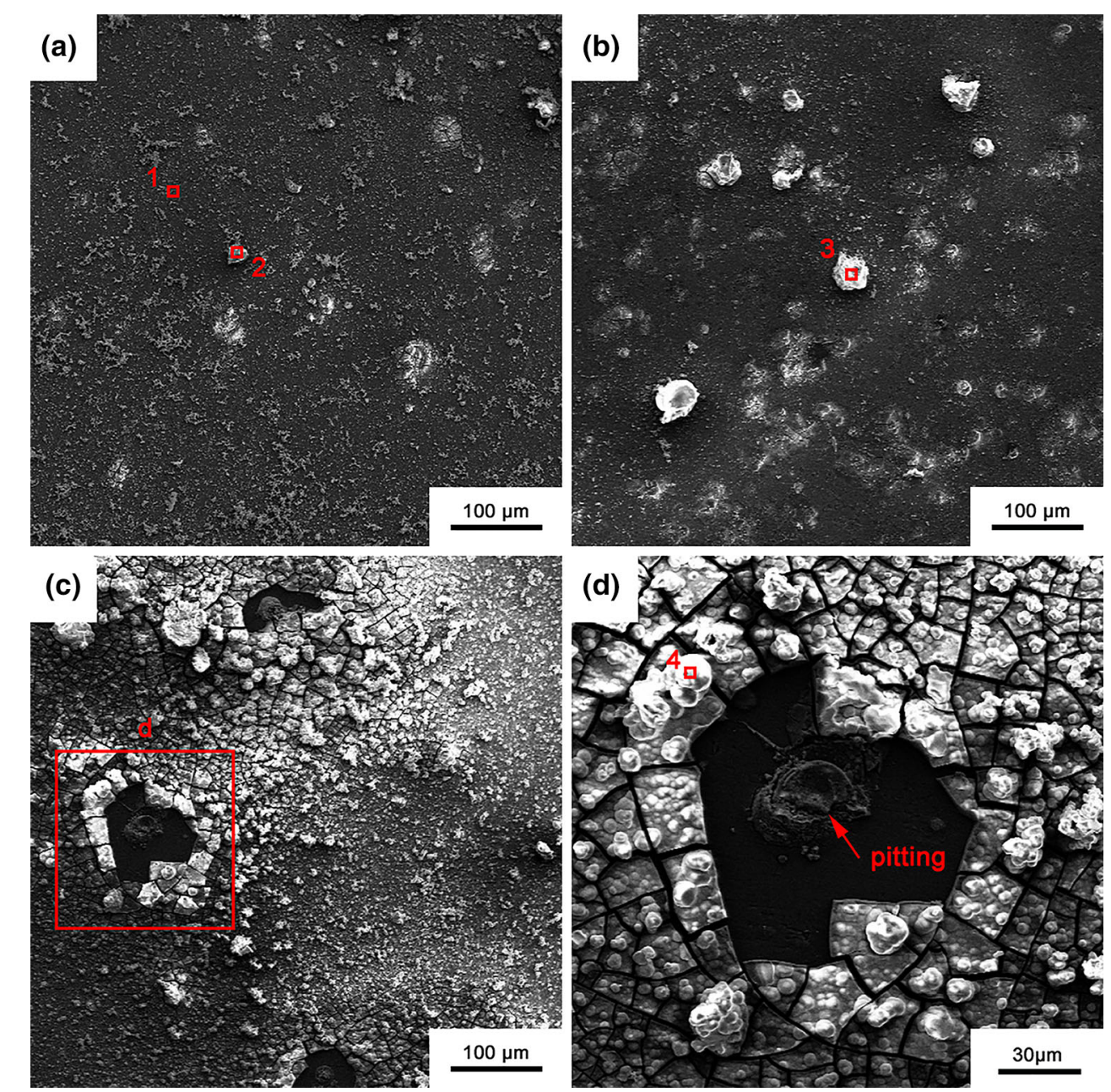

Fig. 7 SEM images of AZ31 Mg sample (after 5\% uniaxial compression) immersed in SBF for 24 h: a TD plane, b RD plane, c 45TD plane, d partial enlargement of 45TD plane in c

Table 5 Elemental compositions of different planes of AZ31 Mg sample (after 5\% uniaxial compression) immersed in SBF for 24 h, spots 1-4 are indicated in Fig. 7

\begin{tabular}{lcccccccc}
\hline Region & \multicolumn{2}{l}{ Elemental composition (wt\%) } & & \multicolumn{2}{c}{ Ca/P ratio } \\
\cline { 2 - 8 } & $\mathrm{O}$ & $\mathrm{Mg}$ & $\mathrm{Al}$ & $\mathrm{P}$ & $\mathrm{Ca}$ & $\mathrm{Na}$ & $\mathrm{Cl}$ \\
\hline Spot 1 (TD plane) & 7.4 & 84.04 & 3.27 & 2.44 & 2.84 & - & - \\
Spot 2 (TD plane) & 24.10 & 55.74 & 1.86 & 7.29 & 10.08 & 0.93 & - & 1.16 \\
Spot 3 (RD plane) & 39.44 & 19.62 & 0.79 & 14.59 & 24.92 & 0.65 & - & 1.38 \\
Spot 4 (45TD plane) & 55.46 & 0.61 & - & 14.38 & 25.65 & 0.61 & 0.73 & 1.71 \\
\hline
\end{tabular}

\section{Conclusions}

(1) The microstructure and texture exhibit distinct anisotropy with respect to the inhomogeneous deformation. Inhomogeneous deformation made the microstructure different obviously. After 5\% uniaxial compression along the TD, the TD plane mainly consists of $\{0001\}$ deformation texture because most grains rotated approximately to the TD axis. The 45TD plane shows some tilt basal texture, and the RD plane keeps the original texture. The amount of the $\{10-12\}$ tension twins in the three planes follows 45TD plane $>$ TD plane $>$ RD plane.

(2) The TD plane performs better in corrosion resistance compared to the 45TD and RD planes. This is benefited from the strong $\{0001\}$ texture inducing a 


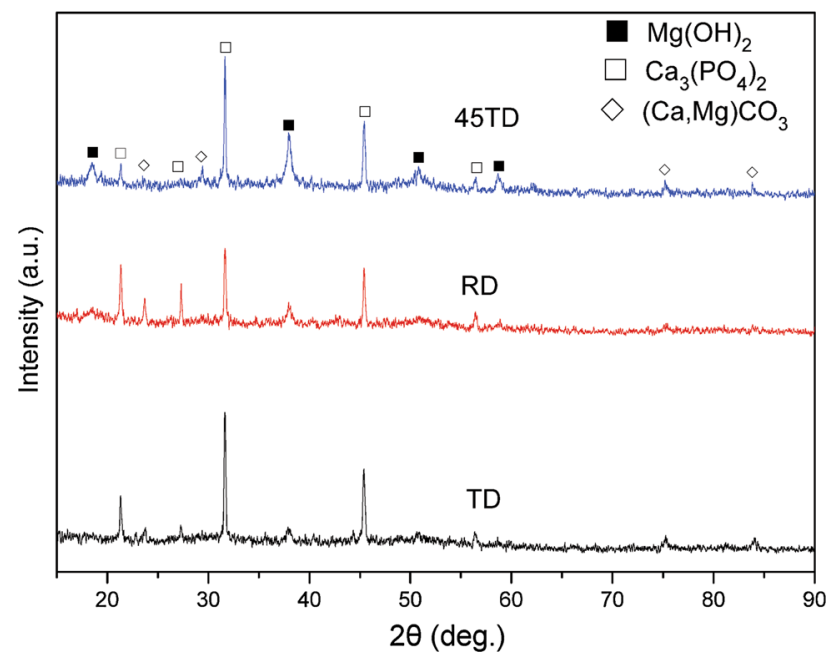

Fig. 8 XRD patterns of the corrosion productions of $\mathrm{AZ} 31 \mathrm{Mg}$ sample (after 5\% uniaxial compression) immersed in SBF for $24 \mathrm{~h}$ : a TD plane, b $45 \mathrm{TD}$ plane, $\mathbf{c}$ RD plane

lower surface energy after 5\% uniaxial compression along the TD.

(3) The 45TD plane shows a high rate of corrosion, and the mount of pitting is greater than that of the TD plane after immersion, which is benefited from the $\{10-12\}$ tension twins after 5\% uniaxial compression.

(4) Both deformation textures and $\{10-12\}$ tension twins play an important role in corrosion resistance. The deformation textures show a positive effect, while the $\{10-12\}$ tension twins affect negatively on the corrosion behavior. Furthermore, the effect of the deformation texture is greater than that of twins in the corrosion.

Acknowledgements This work was financially supported by the National Natural Science Foundation of China (Grant Nos. 51301040 and 51501040), the China Postdoctoral Science Foundation (Grant No. 2016M590591) and the Natural Science Foundation of Fujian Province of China (Grant Nos. 2016J01215 and 2017J01477).

\section{References}

[1] M.P. Staiger, A.M. Pietak, J. Huadmai, G. Dias, Biomaterials 27, 1728 (2006)

[2] R.L. Xin, Y.M. Luo, A.L. Zuo, J.C. Gao, Q. Liu, Mater. Lett. 72, 1 (2012)

[3] Y. Snir, G. Ben-Hamu, D. Eliezer, E. Abramov, J. Alloys Compd. 528, 84 (2012)

[4] H.C. Pan, F.H. Wang, L. Jin, M.L. Feng, J. Doug, J. Mater. Sci. Technol. 32, 1282 (2016)
[5] G.L. Song, R. Mishra, Z.Q. Xu, Electrochem. Commun. 12, 1009 (2010)

[6] Renlong Xin, Bo Li, Ling Li, Qing Liu, Mater. Des. 32, 4548 (2011)

[7] N.N. Aung, W. Zhou, Corros. Sci. 52, 589 (2010)

[8] M. Ascencio, M. Pekguleryuz, S. Omanovic, Corros. Sci. 87, 489 (2014)

[9] M. Ascencio, M. Pekguleryuz, S. Omanovic, Corros. Sci. 91, 297 (2015)

[10] S.-H. Choi, E.J. Shin, B.S. Seong, Acta Mater. 55, 4181 (2007)

[11] B.S. Wang, L.P. Deng, C. Adrien, N. Guo, Z.R. Xu, Q. Li, Mater. Charact. 108, 42 (2015)

[12] B.S. Wang, L.P. Deng, N. Guo, Z.R. Xu, Q. Li, Mater. Charact. 98, 180 (2014)

[13] M.D. Nave, M.R. Barnett, Scr. Mater. 51, 881 (2004)

[14] B. Song, R.L. Xin, G. Chen, X.Y. Zhang, Q. Liu, Scr. Mater. 66, $1061(2012)$

[15] J. Jiang, A. Godfrey, W. Liu, Q. Liu, Scr. Mater. 58, 122 (2008)

[16] S.G. Hong, S.H. Park, C.S. Lee, Acta Mater. 58, 5873 (2010)

[17] J.R. Dong, D.F. Zhang, J. Sun, Q.W. Dai, F.S. Pan, J. Mater. Sci. Technol. 31, 935 (2015)

[18] T. Kokubo, H. Takadama, Biomaterials 27, 2907-2915 (2006)

[19] B.M. Wilke, L. Zhang, JOM 68, 1701 (2016)

[20] B. Niu, P. Shi, D.H. Wei, E. Shanshan, Q. Li, Y. Chen, J. Alloys Compd. 665, 435 (2016)

[21] ASTM G31-72(2004), Standard Practice for Laboratory Immersion Corrosion Testing of Metals (ASTM International, West Conshohocken, PA, 2004). www.astm.org. doi:10.1520/ G0031-72R04

[22] S.H. Choi, B.J. Kim, S.I. Kim, U.S. Yoon, Mater. Sci. Forum 539-543, 1713 (2007)

[23] M.R. Barnett, Mater. Sci. Eng., A 464, 1 (2007)

[24] Z. Shi, M. Liu, A. Atrens, Corros. Sci. 52, 579 (2010)

[25] C.J. Wang, B.L. Jiang, M. Liu, Y.F. Ge, J. Alloys Compd. 621, $53(2015)$

[26] L.C. Zhao, C.X. Cui, Q.Z. Wang, S.J. Bu, Corros. Sci. 52, 2228 (2010)

[27] P. Su, X. Wu, Y. Guo, Z. Jiang, J. Alloys Compd. 475, 773 (2009)

[28] G.D. Zou, Q.M. Peng, Y.N. Wang, B.Z. Liu, J. Alloys Compd. 618, 44 (2015)

[29] H.P. Duan, K.Q. Du, C.W. Yan, F.H. Wang, Electrochim. Acta 51, 2898 (2006)

[30] H. Duan, C. Yan, F. Wang, Electrochim. Acta 52, 3785 (2007)

[31] T.S. Lim, H.S. Ryu, S.H. Hong, Corros. Sci. 62, 104 (2012)

[32] A.S. Gnedenkov, S.L. Sinebryukhov, D.V. Mashtalyar, S.V. Gnedenkov, Corros. Sci. 102, 348 (2016)

[33] S. Zhang, Q. Li, B. Chen, X. Yang, Electrochim. Acta 55, 870 (2010)

[34] M. Liu, D. Qiu, M.C. Zhao, G. Song, A. Atrens, Scr. Mater. 58, 421 (2008)

[35] B.J. Wang, D.K. Xu, J.H. Dong, W. Ke, J. Mater. Sci. Technol. 32, 646 (2016)

[36] B.Q. Fu, W. Liu, Z.L. Li, Appl. Surf. Sci. 255, 8511 (2009)

[37] Y.C. Zhao, G.S. Huang, G.G. Wang, T.Z. Han, F.S. Pan, Acta Metall. Sin. (Engl. Lett.) 28, 1387 (2015)

[38] J. Chen, J.Q. Wang, E.H. Han, W. Kea, D.W. Shoesmith, Acta Metall. Sin. (Engl. Lett.) 29, 1 (2016) 